\section{New treatment for ulcerative colitis?}

Since the aetiology of ulcerative colitis is unknown it is not surprising that an allergic mechanism should have been proposed. Many years ago Andresen ${ }^{1}$ suggested that food allergy was responsible and went on to incriminate cow's milk, eggs, oranges, potatoes, tomatoes, and wheat. Out of all these foods, milk seemed to be the most important. Wright and Truelove $^{2}$ therefore performed a controlled therapeutic trial of various diets in patients recovering from an acute attack of ulcerative colitis. Twice as many patients taking the milk-free diet remained well throughout the year of the study as did controls, while those who relapsed suffered less frequent attacks. The milk-free diet was thought to be beneficial in one out of five patients. At that time, however, the role of lactase deficiency in the genesis of diarrhoea was unknown, and that could have provided an alternative explanation. ${ }^{3}$

Histological examination of the rectal mucosa in active ulcerative colitis often shows increased numbers of plasma cells, eosinophils, and degranulated mast cells. ${ }^{1^{-}-}$Moreover, the histamine content of the mucosa is high during a relapse. ${ }^{8}$ These are the features of an acute (type 1) hypersensitivity reaction and are similar to those found in the bronchi in allergic asthma, in which mast cells sensitised with IgE are thought to rupture and release vasoactive substances. In asthma, this reaction and the associated clinical symptoms may be prevented by the drug disodium cromoglycate (DSCG).$^{9}$ Since mast cells may possibly mediate some of the manifestations of ulcerative colitis gastroenterologists have spent the last seven years wondering whether DSCG might be useful in treating this disease too. The drug has a topical action, so that adequate contact with the mucosa is necessary; this may be achieved by giving it by rectum, but since DSCG is unchanged during transit through the bowel and is not absorbed taking it by mouth may be superior.

Heatley and his colleagues ${ }^{10}$ recently used the drug to treat 26 patients with ulcerative proctitis-inflammatory disease confined to the rectum. DSCG was given both orally (300 $\mathrm{mg}$ day) and as an enema (200 mg) using a double-blind crossover technique with two treatment periods of four weeks. They recorded stool frequency, rectal bleeding, subjective improvement, and sigmoidoscopic appearances. By allotting points for these features they decided that 14 patients had shown a response to DSCG, two had responded to the placebo, and 10 had had no benefit. Unfortunately the degree of inflammatory reaction in the rectal mucosa did not correlate with the clinical or sigmoidoscopic features, but the patients who responded to DSCG had significantly more eosinophils in their rectal biopsies than non-responders.

This study was concerned only with ulcerative proctitis, and the treatment periods were brief. Though data from large series suggest that ulcerative proctitis is related to ulcerative colitis, ${ }^{11-13}$ many clinicians believe that the disease is different because it rarely spreads proximally and is often associated with the irritable bowel syndrome. Mani and his colleagues ${ }^{14}$ have treated 12 patients with more extensive ulcerative colitis using a large oral dose ( $2 \mathrm{~g}$ day) and continuing it for six months. By employing a double-blind crossover method they found that the drug produced statistically significant improvement both in general well-being and in the histological and sigmoidoscopic appearances. Nevertheless, the average number of stools did not change, and diminution of rectal bleeding was variable. Acutely ill patients were not studied, and, though 11 had disease affecting the whole colon, the results of laboratory investigations were normal throughout.

Both these papers suggest that DSCG may be of some benefit in the long-term management of ulcerative colitis, but the $50 \%$ success rate in ulcerative proctitis suggests that it is less effective than corticosteroid enemata, and a formal trial of the two regimens is needed. Furthermore, there is as yet no information about the place of DSCG in the acute, severe attack. Thus for the moment sulphasalazine remains the maintenance treatment of choice. When mild relapses occur, a combination of sulphasalazine and corticosteroid enemata should be used in the first instance; more severe attacks may require systemic corticosteroids. DSCG might be used carefully in all these presentations, but it should not replace established treatment until more is known about its effects. The drug may prove particularly useful in the management of some recalcitrant cases. Moreover, possibly DSCG will eventually prove to have been of greater value in helping to elucidate the complex aetiology of this disease than in its treatment.

\footnotetext{
1 Andresen, A F R, American fournal of Digestive Diseases, 1942, 9, 91. 2 Wright, R, and Truelove, S C, British Medical fournal, 1965, 2, 138. ${ }^{3}$ British Medical Fournal, 1975, 2, 351.

${ }^{4}$ Goldgraber, M B, Kirsner, J B, and Palmer, W L, Gastroenterology, 1960, 38, 596.

${ }^{5}$ Bercovitz, Z T, and Sommers, S C, Archives of Internal Medicine, 1966, $117,504$.

${ }^{6}$ Wright, R, and Truelove, S C, American fournal of Digestive Diseases, 1966, 11, 831 .

- Binder, V, Scandinavian fournal of Gastroenterology, 1970, 5, 707.

${ }^{8}$ Binver, V, and Hvidberg, E, Gut, 1967, 8, 24.

${ }^{9}$ Pepys, J, et al, Lancet, 1968, 2, 134.

1 " Heatley, R V, et al, Gut, 1975, 16, 559.

${ }^{11}$ Farmer, R G, and Brown, C H, Gastroenterology, 1966, 51, 219.

12 Sparberg, M, Fennessy, J, and Kirsner, J B, Medicine, 1966, 45, 391.

${ }^{13}$ Nugent, F W, et al, American fournal of Digestive Diseases, 1970, 15, 321.

'Mani, V, et al, Gut, 1975, 16, 832.
}

\section{Trial by traction}

Despite the frequent occurrence of low back pain and the resulting loss of time from employment or household duties, in most cases the exact mechanism is far from clear. These episodes are generally agreed to be mechanical and of traumatic or degenerative origin, but until we really completely understand the various syndromes treatment is often empirical, and the prescription of manipulation, traction, corsets, and heat and exercises is widespread. The lack of any clear scientific basis makes it difficult to justify continuing with such treatments when their value has not been adequately assessed; so all attempts at controlled trials should be welcomed.

Traction is not only time-consuming for patients, but it also uses a scarce commodity-skilled physiotherapists. So it is a little surprising to find how few adequate clinical trials there have been of this treatment. After the sporadic appearance of uncontrolled observations in $1955 \mathrm{Christie}^{1}$ published a trial comparing traction with a bland tablet in patients with chronic backache with or without signs of nerve root pressure. Traction up to $150 \mathrm{lb}(68 \mathrm{~kg}$ ) was given on a split (frictionfree) couch and sustained for 20 minutes after pain had been relieved. This treatment was continued three times weekly for four weeks. In the event, little difference was detected between the two treatment groups except for a suggestion that traction might help more when root signs were present. Nevertheless, this trial was only on a small scale, the control series was unsatisfactory, and the trial was not double-blind. 